\title{
Empirical Design Considerations for Industrial Centrifugal Compressors
}

\author{
Cheng Xu and Ryoichi S. Amano \\ Department of Mechanical Engineering, University of Wisconsin-Milwaukee, Milwaukee, WI 53212, USA \\ Correspondence should be addressed to Ryoichi S. Amano, amano@uwm.edu
}

Received 22 February 2012; Revised 29 April 2012; Accepted 30 April 2012

Academic Editor: Ashwani K. Gupta

Copyright ( $) 2012$ C. Xu and R. S. Amano. This is an open access article distributed under the Creative Commons Attribution License, which permits unrestricted use, distribution, and reproduction in any medium, provided the original work is properly cited.

Computational Fluid Dynamics (CFD) has been extensively used in centrifugal compressor design. CFD provides further optimisation opportunities for the compressor design rather than designing the centrifugal compressor. The experience-based design process still plays an important role for new compressor developments. The wide variety of design subjects represents a very complex design world for centrifugal compressor designers. Therefore, some basic information for centrifugal design is still very important. The impeller is the key part of the centrifugal stage. Designing a highly efficiency impeller with a wide operation range can ensure overall stage design success. This paper provides some empirical information for designing industrial centrifugal compressors with a focus on the impeller. A ported shroud compressor basic design guideline is also discussed for improving the compressor range.

\section{Introduction}

New compressor designs always must meet the customers' needs with the shortest time to market, low cost, and improved performance. To push the design to state of the art aerodynamic performance, the structure design also needs to meet a suitable performance life of the compressors. Mechanical integrity is one of the important parts of the centrifugal compressor design. Mechanical constraints are usually negative factors for aerodynamic design, for example, mechanical constraints require thick blade for reliability but hurt impeller efficiency. The purposes of the mechanical analyses are to provide all compressor components within a reasonable time duration to sustain the aerodynamic and centrifugal force, and eigen frequencies do not match critical excitation frequencies [1]. The safety factors of the mechanical design had been reduced dramatically compared with "old fashioned" design. Due to the nature of the Finite Element Analysis (FEA) tools and material property improvements, the safety factor of a modern industrial compressor design normally is set to 7 to $12 \%$. The mechanical requirements need structure designers to have better practice to allow more freedom to aerodynamic designers and to keep all the components at the lowest weight and the lowest cost.
Design of a long lifetime single component of compressors is not a goal for designers. Emphasis on improving efficiency has been a primary issue, but this also is not as important as in the past. The development cost and development time is also a key factor that needs to be considered for a modern compressor design. Industrial compressor design expects a state-of-the-art performance compressor without making a second build for less cost and short development time. For achieving this goal, compressor design engineers need to have multidiscipline knowledge of centrifugal compressor design. Detailed design considerations can reduce the time to perform the advance design studies and laboratory investigations. The wide variety of design subjects represents a very complex design world for compressor designers. One purpose of this paper is to provide information in an aerodynamic point of view to understand the overall design before starting the detailed design process of a centrifugal compressor. The paper also summarizes important aspects of the centrifugal compressor design for industrial compressor designers and scientists.

The compressor market and business model has changed in the last few decades. Industrial compressor design now requires designing for success in the marketplace, not just for scientific experiments. In the past, compressor designers 
developed a new compressor in the development group and passed the design to manufacturing. The manufacturing group would evaluate how to make it at the lowest cost, and some designs were rejected because they could not meet the market requirements. The new development model requires the compressor designer to design for market, manufacturing, and end users. New business concepts have been proposed $[2,3]$ in which the design also considers an integrated system of manufacturers and end users. The new compressor developments become a complex system task. Minimizing manufacturing cost of the compressor design is not enough. The compressor design must consider all aspects of the manufacturing and end users. If surplus is defined as the total profit of manufacturing, end users, and aftermarket, the compressor's new development will focus on the design for maximum surplus. Therefore, in the compressor design stage, many choices of design options need to be considered before the final design, and discussions must consider the surplus value. It is essential that design engineers begin to perform a compressor design with full understanding of all aspects of the design considerations [4-8].

To reduce manufacturing cost, many high volume compressor manufacturers, for example turbocharger, often use the flow cut for different applications. The flow cut uses the same defined blade geometry for multiple flows and a similar or lower pressure ratio. This is different from scaling, in that the impeller blade and any diffuser vane geometry maintain the same definition. A brief introduction of the flow cut is also discussed in this paper.

With the development of computational science and computer hardware, design engineers rely on quality models to establish the physical relationships among diverse thermodynamic, geometric, and fluid dynamic parameters that govern turbomachinery performance [9-26]. Although CFD has helped to design many successful industrial compressors and has become an important tool in industrial compressor design, multidomain optimisation is still very time consuming. Most CFD optimisations still focus on the component [22]. When the compressor inlet flow is reduced, the compressor experiences an unsteady flow phenomena surge and rotating stall. These instabilities can cause noise nuisance and critical operating conditions with strong dynamical loading on the blades. Therefore, they cannot be tolerated during compressor operation. With the reduction of the compressor inlet flow, a rotating stall occurs in the impeller, or diffuser or scroll. If the compressor inlet flow continues to reduce, the rotating stall eventually will drive the compressor into a surge [27-32]. A rotating stall is an unsteady and threedimensional flow phenomenon. CFD simulation is still a big challenge. The flow range of a centrifugal compressor can be extended by allowing gas to bleed from a ring of holes or a circular groove port around the compressor casing at a point slightly downstream of the compressor inlet. This type of the compressor called ported shroud compressor. Ported shroud forces a simulation of impeller stall to occur continuously, allowing some air to escape at port location inhibits the onset of surge and widens the operating range. The flow inside port is unsteady and complicated when compressor stalls. CFD guides ported shroud design is still very time consuming and less reliable. Some design practices for a ported shroud impeller casing [33] are discussed for improving the compressor operational range.

\section{Industrial Centrifugal Compressor}

Centrifugal compressors are widely used in automotive, marine turbocharging, oil and gas, aerospace, and distributed power applications because of their compact design and high stage pressure ratio. With different types of applications, the structural characteristics of the compressors have two basic types, that is, horizontal split and vertical split, as shown in Figure 1. Horizontal split type compressors are applied for low-to-medium pressure service, as shown in Figure 1(a). This type of casing is split along the rotor shaft and bolted at the split line. The bearing and seal sections allow easy disassembly and assembly via the inspection cover, without having to remove the upper casing. A vertical split compressor is easy to access the gears, bearings, seals, and be repaired on site. However, due to the large crossing area in the splitting surface, it is difficult to prevent gas and lubricant oil leakage. A vertical split compressor is applied for mediumand high-pressure service, as shown in Figure 1(b). This type of compressor consists of an inner casing and an outer casing. The inner casing forms a single unit with the head, bearing, and seal and is fixed to the outer casing by shearing. The nozzle can be attached to the top, bottom, or side in accordance with client specifications. Both bearings and seals can be inspected without removing the inner casing. However, the manufacturing cost and installation cost may be higher than for a vertical split compressor. It is also not easy to access the gear, bearings, and seal. For combining the advantages of both split types, a hybrid split has become popular. For some applications, the gearbox can be a vertical split, and the compressor stage can use a horizontal split, as shown in Figure 1(c).

\section{Impeller Design Methodologies}

The impeller is a key component to influence overall performance of a centrifugal compressor [5]. The efficiency of centrifugal compressors has increased dramatically, especially low-pressure ratio centrifugal compressors. A major challenge for a centrifugal compressor design is to keep a high efficiency level at a state of the art and to increase the compressor operating range [27-33]. Increasing the compressor operating range without sacrificing compressor peak efficiency is difficult to achieve. Aerodynamic engineers not only need to understand the surge physics but also need to apply design experience to the design. Another important objective for impeller design is to reduce the manufacturing cost. Manufacturing cost could be reduced when designs for manufacturability are effectively considered. The impeller should meet requirements to be easily withdrawn from a casting mold without destruction and disassembly of the mold for a casting impeller. This requires the lean angle of the blade to change linearly with the impeller radius and axial direction, as shown in Figure 2. All these considerations 


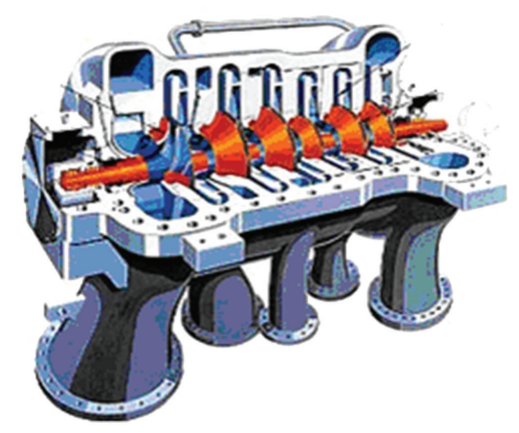

(a) Horizontal split compressor

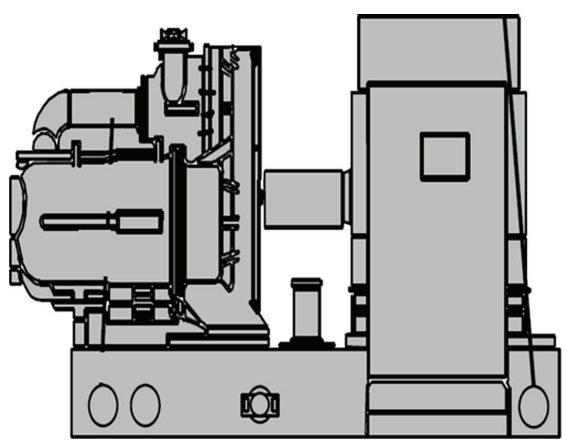

(b) Vertical split compressor

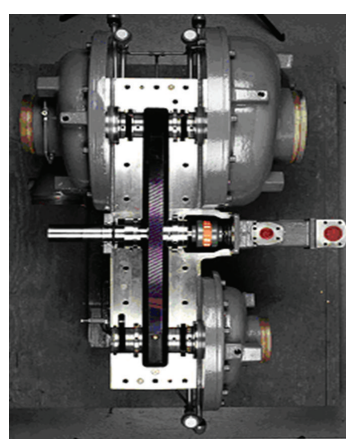

(c) Hybrid split compressor

FIgURE 1: Compressor split types.

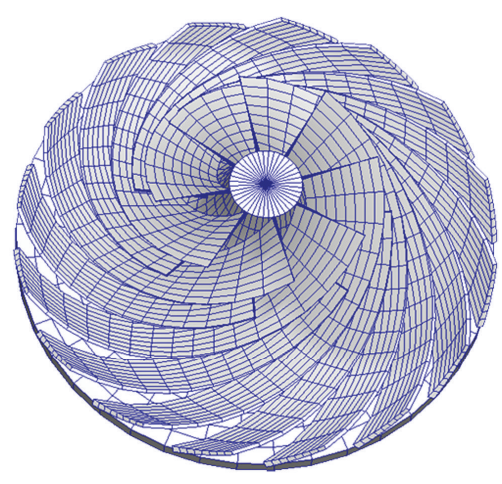

FIGURE 2: Impeller for manufacturing.

for design will help the final design to meet the compressor design target with fewer design iterations.

Different designers may have different methodologies for impeller developments. What kind of area distributions, curvatures, velocity, or pressure profile will lead to a good design is strongly dependent on the designers' practice and experience. Two totally different design philosophies could produce similar performance. For example, two impellers designed by Garret and Pratt Whitney [7], as shown in Figure 3, had different shapes with similar performance at the design point. The impeller designed by the author also presented different features, which also provide a good performance. It is shown that, if design follows basic design guideline, a wide range of solutions to the design can be used.

The authors' design, as shown in Figure 3, is an example of a recently developed single-stage centrifugal compressor. At the design point, the total to static stage pressure ratio was about 3.7, and the flow coefficient was about 0.12 . The running clearance at the impeller tip was $4.5 \%$ of the impeller exit blade width. Six builds were assembled and tested based on the ASME PTC-10 test procedure [34]. The compressor performance obtained from an average of six build tests is shown in Figure 4. The differences of test results for different builds for adiabatic efficiency and head coefficient were within $\pm 0.5 \%$ and $\pm 0.75 \%$, respectively. The test uncertainties for total pressure (in psi), static pressure (in psi), and temperature (in Fahrenheit) were $\pm 0.25 \%, \pm 0.2 \%$ and $\pm 0.5 \%$, respectively, based on uncertainty analysis [14]. Test results showed that the compressor performance was encouraging at both the design and the off-design point. The design met the low-cost target and allows large manufacturing tolerances. The insensitivity of the impeller surface finish and large tip clearance makes it easy to assemble.

\section{Impeller Geometry}

The initial design of a centrifugal compressor always begins with requirements from customers or marketing analysis. Designers select basic configurations and provide basic performance to customers or marketing by using their experience data. Aerodynamic designers also need to provide an estimation for the compressor's basic geometry to engineers in other disciplines. For example, rotor-dynamic engineers and bearing designers rely on the impeller geometry information to perform their work. Although the basic geometry design is not intended to yield optimization of the impeller, it can accelerate the overall design process and reduce the development cost.

Before aerodynamic designers determine the basic impeller geometry, the rotational speed of the impeller needs to be selected. If there are no special requirements for rotational speed, we normally optimize rotational speed based on the Balje's charts $[35,36]$ by using optimal specific speed. Although Balje's charts are not very accurate tools, they are sufficient enough to provide the initial estimate for impeller geometries.

During the initial design, the important information needed for bearing designers and rotor-dynamic engineers is impeller weight. Aerodynamic designers can estimate impeller sizes based on the required gas flow, pressure ratio, and impeller rotational speed. Our design practices showed that the weight of the impeller is the function of the impeller diameter. Figure 5 summarizes the relationship between the impeller diameter and the weight for sixteen ASTM A564 stainless-steel unshrouded impellers. The impeller weight mainly is determined by the impeller disk; the blades only contribute a very small portion of the weight. Therefore, we plotted impeller weight and diameter relation in one figure 


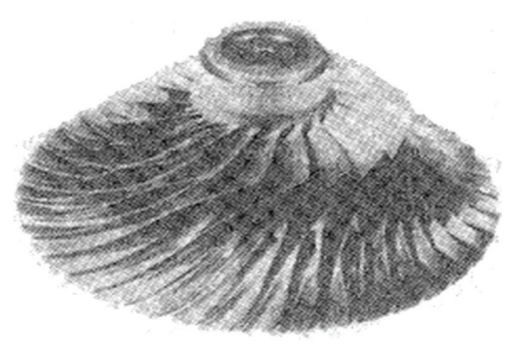

Garret design

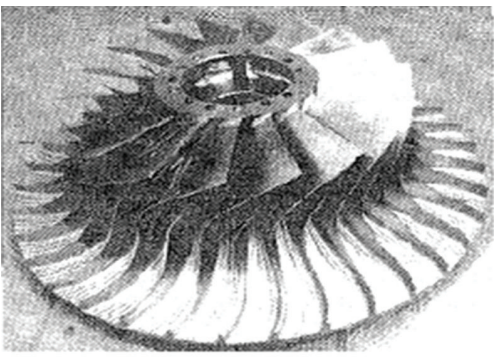

Pratt Whitney design

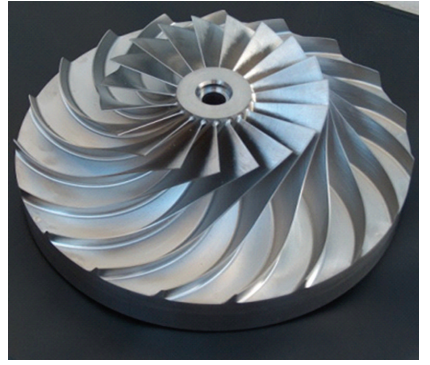

Author's design

Figure 3: Different impeller designs.

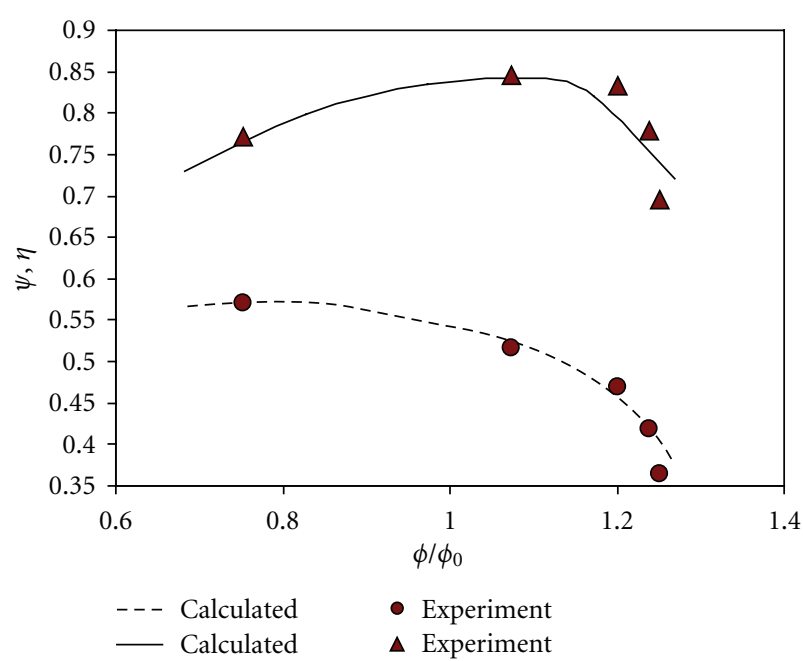

FIgURE 4: Single stage compressor efficiency and head coefficient versus flow coefficient (upper curve is the adiabatic efficiency, and lower curve is head coefficiency).

for all designed unshrouded impellers with different blade counts and with or without splitters.

In an initial stage of compressor design, selections of the impeller inlet, the outlet velocity vectors, and the choice of blade numbers are the key initial design decisions. Velocity vectors may be obtained through a mean-line program. The experience data show that both the inlet blade numbers and the exit blade numbers are a function of stage pressure ratio. Relationships between the numbers of blades and the stage pressure ratio are shown in Figures 6 and 7 for with and without splitter impellers, respectively. In general, high-stage pressure causes a blade-loading increase, and the impeller needs more blades to distribute loading. Variations of the numbers of blades at a similar pressure ratio were due to the size of the impellers. For a smaller-sized impeller, manufacturing capabilities may limit the number of blades. Impeller sizes plotted in Figures 6 and 7 are in the range from 2 inches to 45 inches. The machine performance requirements and manufacturing feasibilities are factors to determine whether to use splitters or not.

The inlet blade height is determined by the design inlet flow rate and the impeller hub radius. The inlet hub radius is

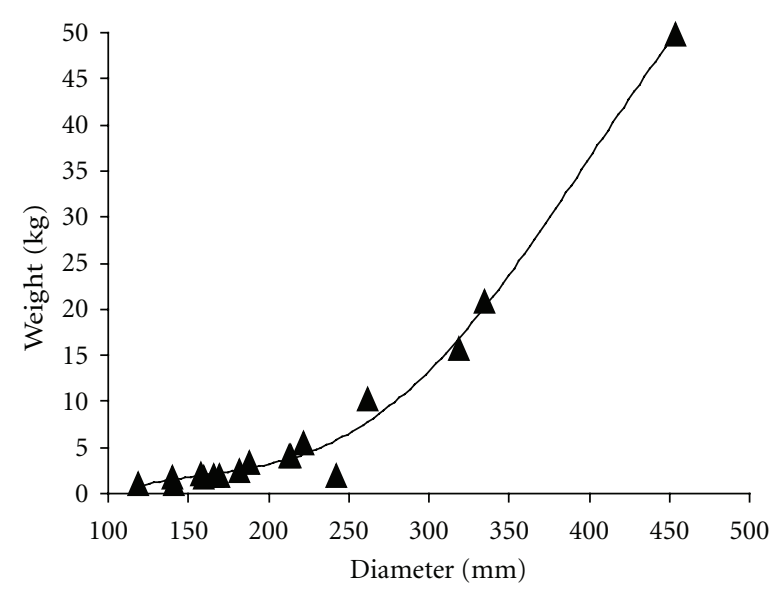

FIgURE 5: Impeller weight with diameter.

determined by the attachment of the impeller. For overhung impellers, the inlet hub radius normally is selected in a range between $10 \%$ and $20 \%$ of the impeller tip radius. For the shaft and bolt through the impeller, selections of the inlet hub radius are based on stress requirements.

The blade thickness at the inlet and the discharge was determined mainly by tensile and bending root stresses at the leading edge and the blade exit. FEA calculations and stress tests showed that blade root stresses are mainly caused by the centrifugal force. The blade high was a key factor to impact the blade root stresses. The mean-line thickness at the inlet and the exit was determined by the blade heights at the inlet and the exit, as shown in Figures 8 and 9. Experience showed that the blade thickness changed linearly with the blade height.

The three-dimensional features of the impeller blade are dependent on the engineers' experience and on stress limitations. The modern impeller is normally a three-dimensional design. The wrap angle, lean angle, and back sweep angle use a larger value than those in the past. The large wrap angle can reduce the camber of the blade but increase the frictions of the fluid. A large lean angle permits blade design at all blade sections with the desired shape. Leaning the blades creates a back-sweep and retains purely radial fibers, which are beneficial for bending moments. Experience showed that impellers with a back sweep generally have high efficiency. 


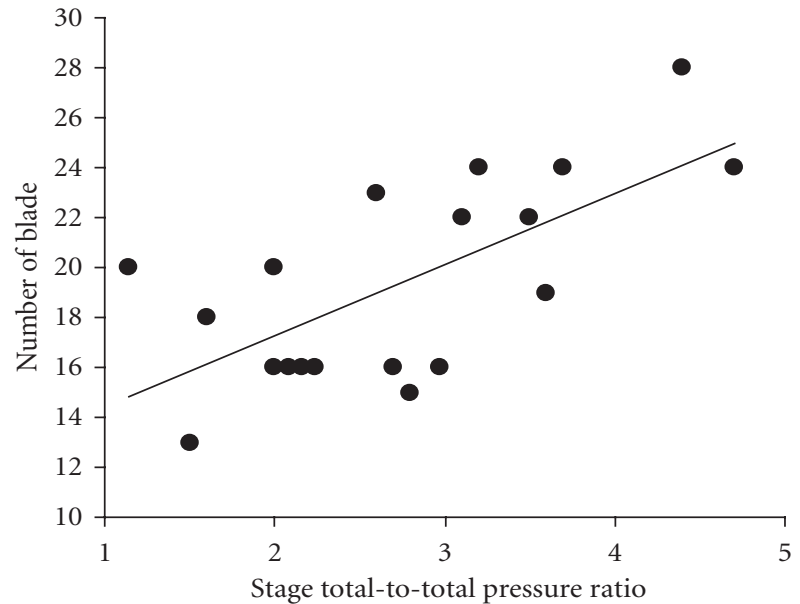

Figure 6: The number of blades at the inlet versus stage pressure ratio.

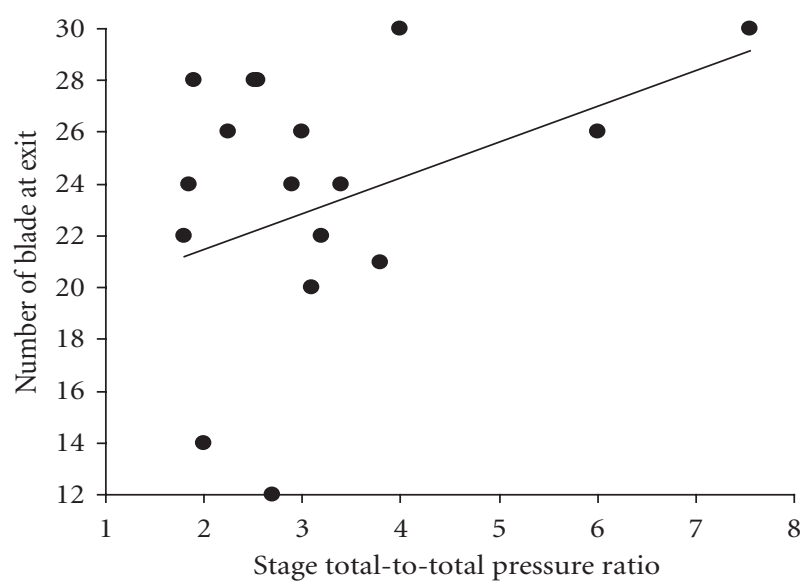

Figure 7: The number of blades at the exit versus stage pressure ratio for split impellers.

\section{Reynolds Number and Surface Finish}

The Reynolds number or the Ross by number has significant impacts on the impeller maximum surplus value. Fundamental fluid dynamics theory $[37,38]$ shows that the flow inside a pipe for a different Reynolds number represents different flow patterns. This is also true for flow inside impeller blades. Experience showed that if there is a flat velocity profile at the inlet between two impeller blades or diffuser vanes, the flow development along the flow channel presents different profiles with different Reynolds numbers. For low Reynolds number flows, the exit velocity profile is almost parabolic and only with a small portion of a flat profile. For high Reynolds number flows, the exit velocity profiles have large flat profiles.

The peak meridional velocities for high Reynolds number flows are normally located at the hub pressure sides of the blade due to potential flow effects. Low Reynolds number flow regions are located near the suction side of the blades. The viscous jet and wake interaction causes flow separations.

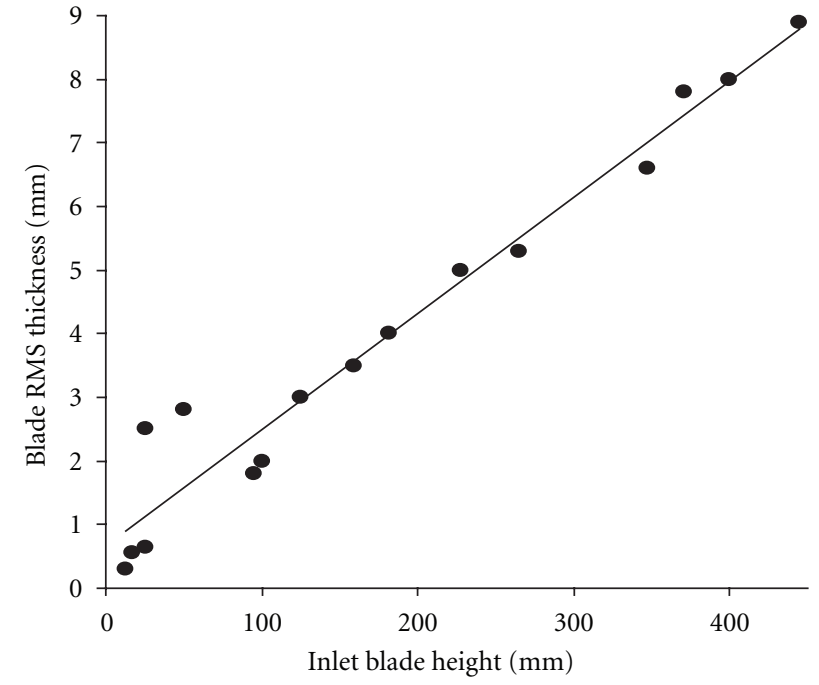

FIGURE 8: Relationship between impeller inlet RMS thickness and inlet width.

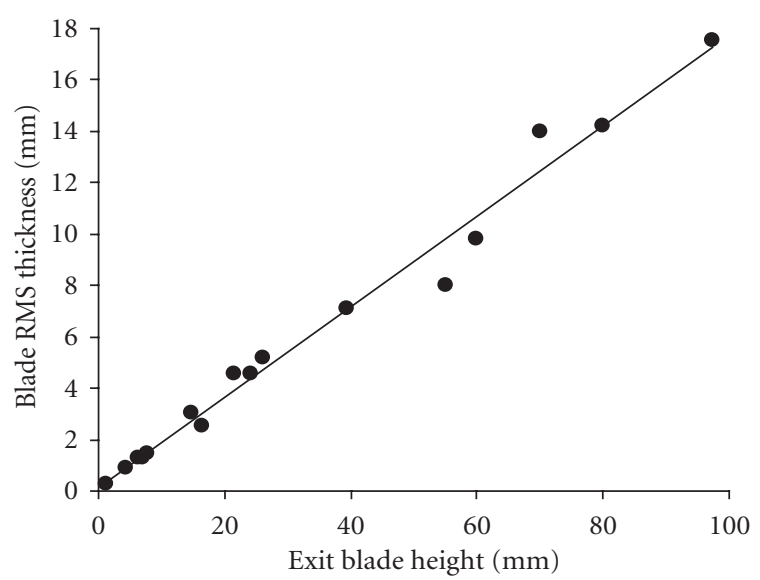

FIGURE 9: Relationship of impeller exit RMS thickness and tip width.

The Reynolds number also strongly influences secondary flow patterns. Increasing the Reynolds number increases the strength of the clockwise secondary passage flow circulation. Reducing pressure on the suction velocity gradient increases the flow circulation of the counter clockwise secondary flow. The optimum design should try to offset each other to minimize the secondary flow losses.

The machining and casting of centrifugal compressor impellers and other components result in an inherent surface roughness. The sizes and forms of roughness depend on the manufacturing process. The levels of the surface finish represent the manufacturing cost. It is very important to balance manufacturing cost and performance. Surface finish requirements for different designs have different requirements. A detailed discussion on surface finish and Reynolds number can be found in reference $[39,40]$. Loss due to the 


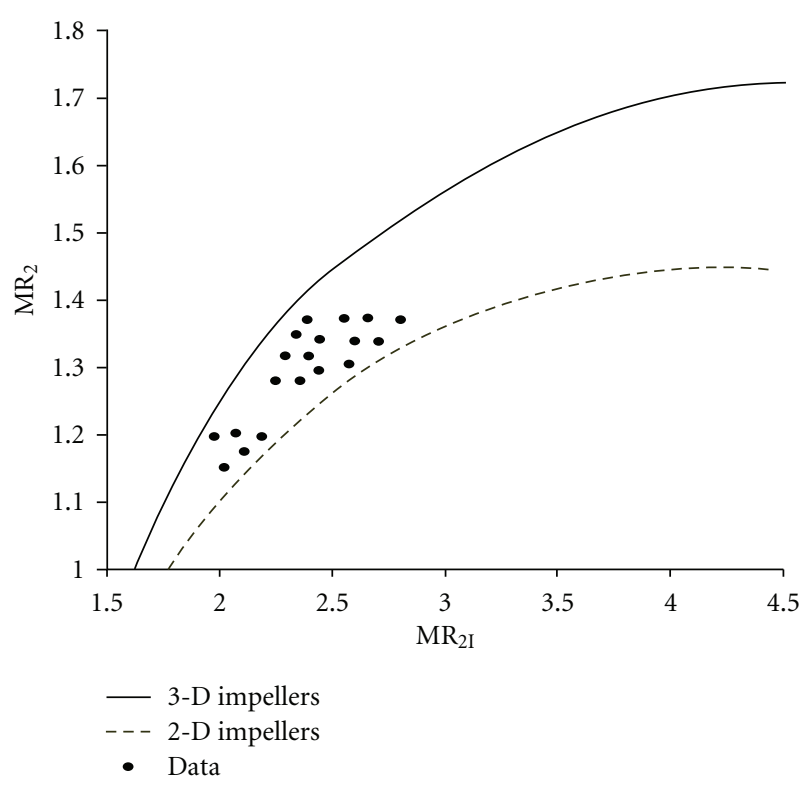

FIgURE 10: Relationship of $\mathrm{MR}_{2}$ versus $\mathrm{MR}_{2 I}$.

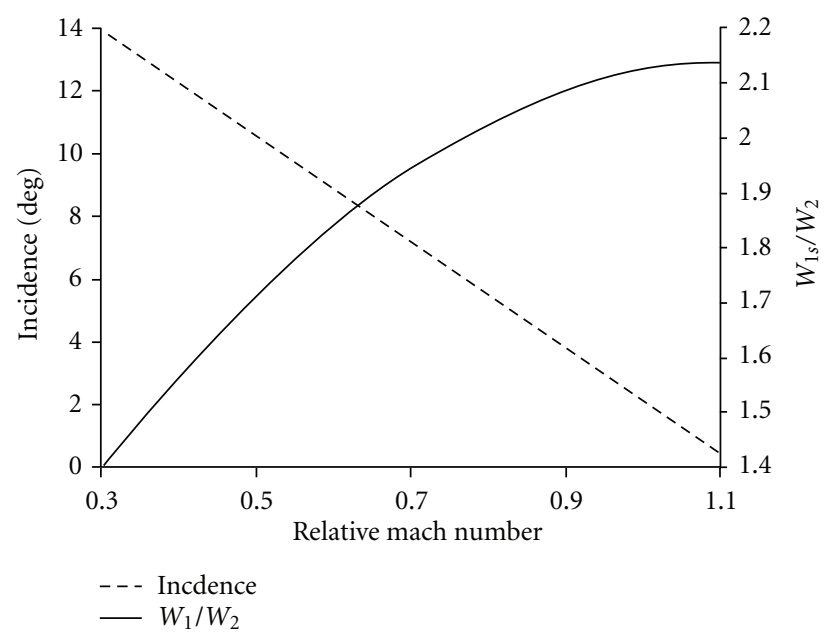

FIGURE 11: Stall incidence and relative velocity ratio versus Mach number.

surface finish can be represented as wall friction. Wall friction is the function of Reynolds number and can be written as

$$
\frac{1}{\sqrt{f}}=1.74-2 \log _{10}\left(\frac{k}{B_{2}}+\frac{18.7}{\operatorname{Re} \sqrt{f}}\right) .
$$

This equation can be solved by using a simple computer program or spreadsheet.

\section{Impeller Aerodynamic Design}

One important guideline for impeller aerodynamic design is to set a reasonable diffusion ratio. The diffusion of the impeller can be represented by velocity ratio, diffusion factor, and relative Mach number ratio. The ratio of the relative Mach

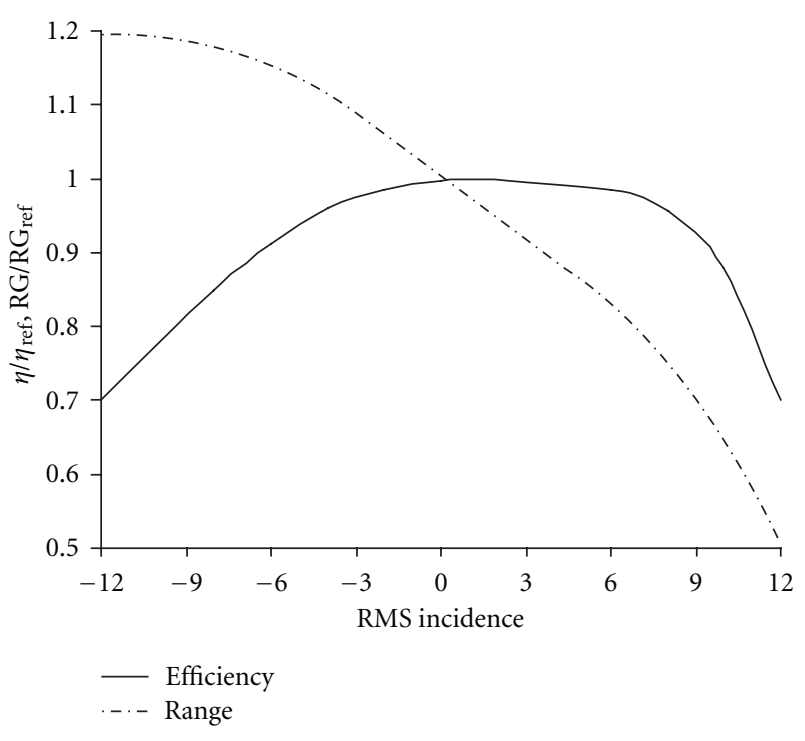

FIgURE 12: Incidence versus efficiency and range.

number was used in this discussion because it can avoid the one-dimensional assumption at the inlet. MR2 is defined as the ratio of the relative Mach number at the impeller inlet to the average Mach number at the impeller exit. Figure 10 shows the upper and lower boundaries for maximum deceleration likely to be achieved for two-dimensional and threedimensional impellers [8]. The experience data fell inside the theory boundaries, and the Mach number ratio MR2 fell between 1.15 and 1.4, giving a good overall performance. The upper boundary of MR2 of 1.4 for an industrial compressor and 1.7 for jet engine impellers are reasonable expectations. Our experience also indicated that a large diffusion might cause a large loss. The ratio of the Mach number can be selected within a large range. An important factor to impact the selection of diffusion level is the inlet Mach number. Figure 11 is a relationship between the relative velocity ratio, the incidence, and the inlet relative Mach number for a typical industrial impeller. It can be seen that diffusion is not an absolute parameter, which influences the stall of the compressor. It is worthwhile to point out that this test impeller was stalled first at the inducer. The inducer shroud velocity represented the rotational speed.

Traditionally, the impeller inlet incidence is set to zero at the design condition. Modern impeller designs need not only to consider maximum efficiency at the design point, but also to consider the manufacturing cost and the off-design performance for the whole operating range [8]. Inlet blade angles are not necessary the same as the inlet relative flow angles. Experience data in Figure 11 shows that changes of the inlet flow incidence impact both the efficiency and the operating range of the impeller. Figure 12 shows that little negative incidences could raise the impeller operating range. However, when the negative incidence increased to a certain level, the operating range did not enlarge and efficiency dropped significantly. The impeller design should avoid this situation. 
Estimations of the impeller exit width are critical for both the primary performance estimation and the basic dimension setup. The major impacts of the impeller blade exit width are the flow capacity and the pressure ratio of the stage. It is difficult to calculate the impeller exit width accurately in a simple way. The Rodgers diffusion factor equation [41] provided a good estimated value for the impeller exit width $\left(B_{2}\right)$. If the mean meridional blade length can be estimated as

$$
L=\frac{2 \pi\left(r_{2}-r_{1}\right)}{4},
$$

then the impeller exit width can be estimated as

$$
\begin{aligned}
B_{2}= & \frac{10\left(D_{2}-D_{s 1}\right)}{1+\left(W 2 / W_{1}\right)}\left[\mathrm{DF}-1+\frac{W 2}{W_{1}}-\frac{\pi D_{2} C_{\tau 2}}{2 L z W_{1}}\right] \\
& -\frac{\left(D_{s 1}-D_{h 1}\right)}{2} .
\end{aligned}
$$

Secondary flows inside the impeller are caused by an imbalance of the static pressure and the kinetic energy. One of the typical secondary flows, the horseshoe vortex, has been well documented. It is shown that the strength of the secondary flows is governed by the vortex starting conditions. The further development of the vortex is determined by the conservation of angular momentum. The impeller meridional blade profiles influence the secondary flow loss level and the laminar viscous dissipation function can estimate the secondary flow loss due to the blade profiles [8]. We have

$$
\Delta H_{l}=N \int \mu\left[2\left(\frac{\partial u}{\partial x}\right)^{2}+2\left(\frac{\partial v}{\partial y}\right)^{2}+\left(\frac{\partial u}{\partial y}+\frac{\partial v}{\partial x}\right)^{2}\right] d V
$$

Tip clearance cannot be avoided for unshrouded impellers. Bearing clearances and manufacturing tolerances of the impeller and the intake ring control the minimum impeller tip clearance. The minimum tip clearance is normally defined at the maximum rotational speed with hot weather conditions for most motor-driven compressors. For compressors installed in the same shaft with a gas turbine, the minimum compressor tip clearance was estimated when the compressor was operating at maximum rotational speed with hot weather and with the machine overall net axial thrust load towards the compressor. The tip clearance increases quadratically with the impeller rotational speed if other operating conditions do not change. The tip clearance impacts the overall compressor performance because it increases the magnitude of the secondary flow inside the impeller blades and produces strong tip vortices. The tip clearance flow transports a low momentum fluid from the suction side to the pressure side of blades. The circumferential center of the secondary flow is dependent on the size of the tip clearance. Secondary vortices are located near the shroud side for small clearance, whereas secondary vortices may spread to the center and even the hub of the flow channel for a large tip clearance impeller. The clearance distribution affects the wake formation and the location at the impeller exit.

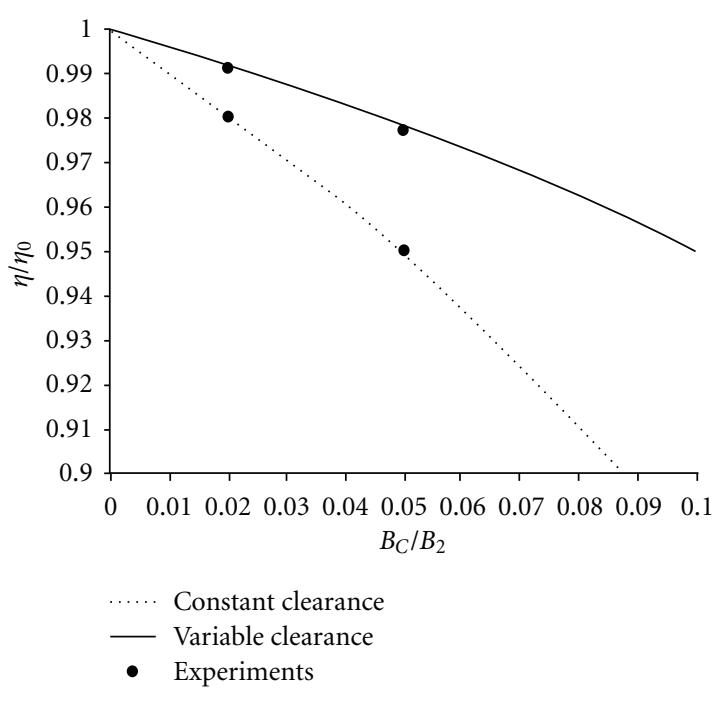

FIGURE 13: Compressor efficiency change versus clearance.

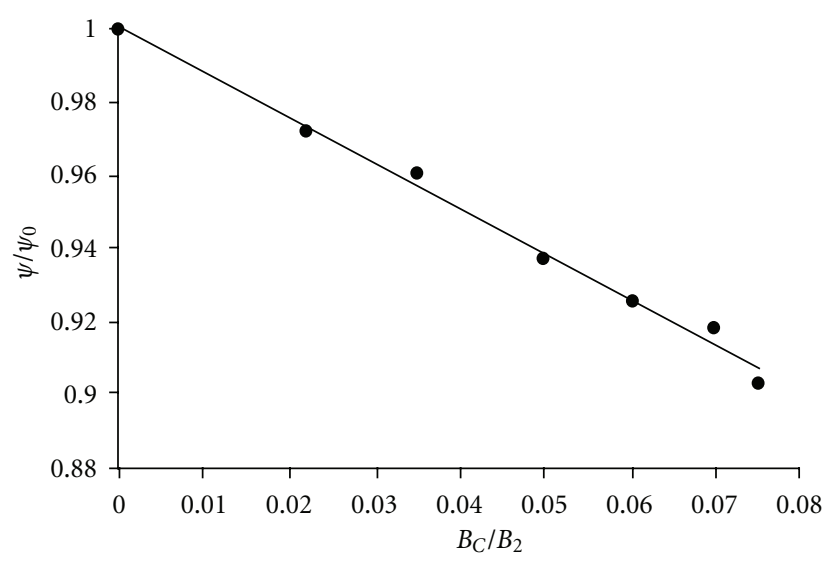

FIgURE 14: Head coefficient change with tip clearance.

A large clearance at the leading edge results in a low-energy center close to the suction side of the blade. Reducing the clearance at the leading edge, the wake moves towards the pressure side of the blade. The tip clearance setting depends on the compressor's maximum surplus value. There are several methods to reduce the tip clearance losses. Figure 13 shows that variable clearance could significantly improve the stage efficiency of compressors. The tip clearance changes the compressor stage head and capacity. Test data indicated that the head coefficient almost changed linearly with the tip clearance, as shown in Figure 14, and the flow coefficient followed a secondary order curve with clearance, as shown in Figure 15.

With the manufacturing technology improvement and design system improvement [42, 43], modern impellers always are designed in a three-dimensional shape. It is very important to understand the impact of the three-dimensional feature on performance and structure. Lean is one of the critical three-dimensional features. In general, both negative and positive lean improves the peak efficiency. One of the design examples for lean effects is shown in Figure 16. 


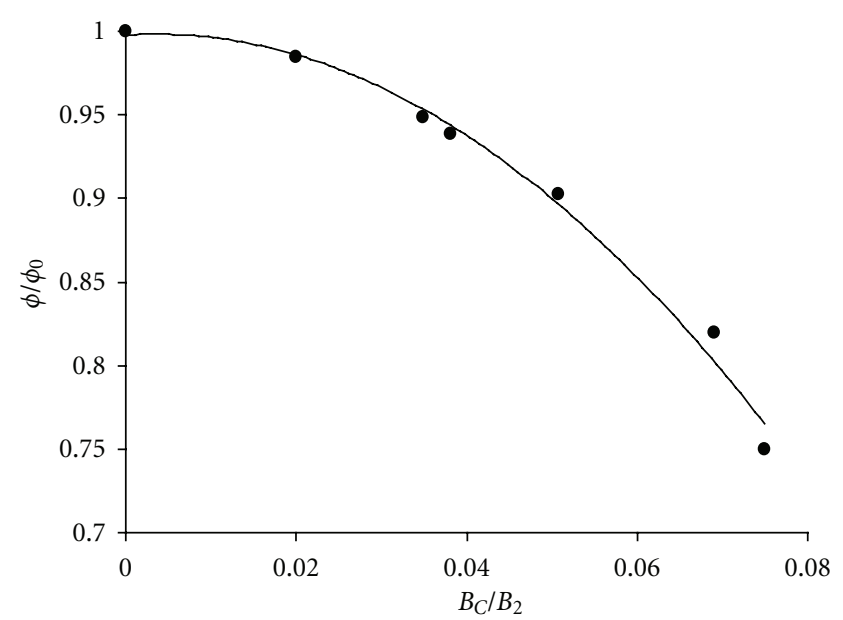

FIGURE 15: Flow coefficient change with tip clearance.

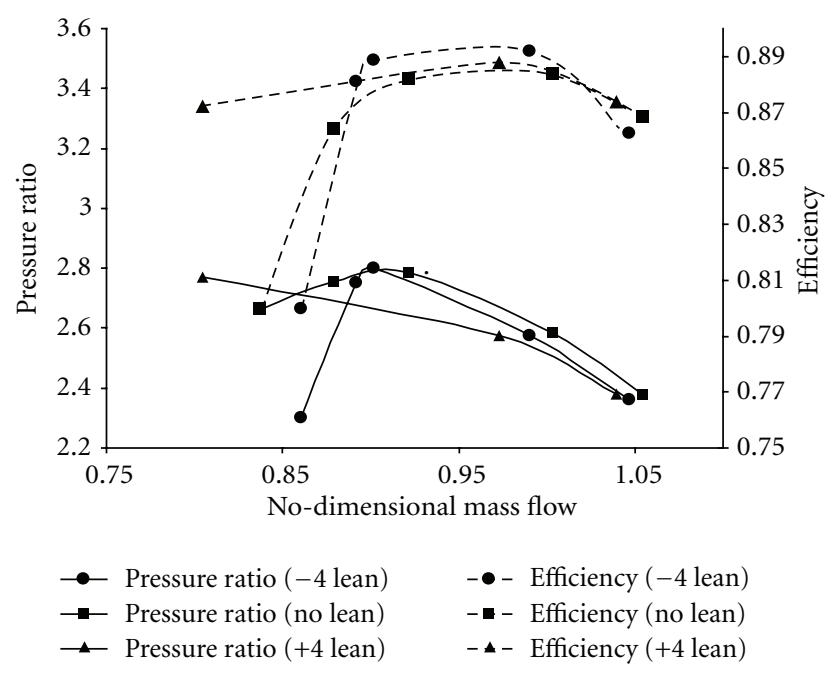

Figure 16: Compressor performance for a lean blade.

Negative lean has the best peak efficiency, while positive lean has a wide operating range. It can be seen from Von Mises stress contour plots in Figures 17 and 18 that the Von Mises stress is the highest for a negative four-degree lean on a suction surface, and the stress is the lowest for a four-degree lean. However, the pressure side stress contours show the lowest leading edge stress area for a negative four-degree lean design compared with other cases. The negative lean has maximum stress for both the leading edge and the trailing edge while the positive lean has the lowest maximum stress in all locations. The highest stress areas for the positive lean are less than the negative lean and no lean cases. The bore stress and back face stresses are similar because the blade thickness distribution is similar. It can be seen that a small positive lean can reduce the peak stress.

\section{Impeller Flow Cut}

For large volume low-cost compressors, for example, automobile turbochargers, the impeller flow cut is always used for meeting different flow and pressure ratio requirements with minimum manufacturing cost. A flow cut is defined as a change to the impeller blade height or a change to the shroud contour while following the same hub contour and blade angle definition as the original impeller design. This allows a single manufacturing method to be used for the base impeller, plus a machining operation to adjust the blade height and the flow capacity of the impeller. Achieving the objectives for high efficiency and end users' cost of a compressor installation are always in conflict with each other. The flow cut of a compressor stage is one of the important activities of centrifugal compressor manufacturers to achieve a certain performance level with minimum cost. A theoretical equation provides the basic information, but the empirical performance effects on the compressor stage are very important to the compressor manufacturers. Figure 19 shows the original impeller (Figure 19(a)), the shroud contour cut (Figure 19(b)), and a diameter cut (Figure 19(c)). Modern impeller design normally has a bigger back sweep angle, as shown in Figures 2 and 3. The diameter cut, as shown in Figure 19(c), affects the impeller performance at a significant level. Therefore, the diameter cut is less popular than the shroud contour cut.

Here we present some test experience for both the shroud and the diameter contour cut. The shroud contour cut (or extend) is defined as the percentage of the local blade height. Most of time, manufacturers extend or trim the shroud contour the same percentage of the impeller inlet and exit blade heights. For large industrial compressors (choke flow larger than $\left.1000 \operatorname{ICFM}\left(0.472 \mathrm{~m}^{3} / \mathrm{s}\right)\right)$, the flow changes normally near linear to the contour change. The major impacts of the flow cuts on the compressor performance are the compressor stage efficiency and the surge flow or the operating range (RG). Figure 20 is the head coefficient at surge point changes with the impeller contours, where the surge point defined here is the operation point at which the compressor stage adiabatic efficiency is $55 \%$. It is shown that the head coefficient at the surge increased as the contour increased. This may be because when the contour increases, the cold tip clearance remains the same during the tests for all the contours. For a larger contour, the tip clearance percentage relative to the impeller exit blade height is smaller, and the surge margin improves. This may be for the same reason. When the contour increases a little, the stage efficiency increases until the design penalty away from the design point is larger than the clearance loss reduction, the compressor efficiency starts to drop, as shown in Figure 21. Test results also suggest at an increased contour, a broader range of high efficiency exists. Testing also indicates that the point of peak efficiency is not proportional to the change in the area of the impeller inducer and the exit geometry. It is interesting to see that the flow corresponding to the peak efficiency increases as the impeller contour increased, as shown in Figure 22. It is important to make the flow cut to ensure the peak efficiency at the operating flow.

Although the diameter cut is less popular than the shroud contour cut, understanding fundamental information and 


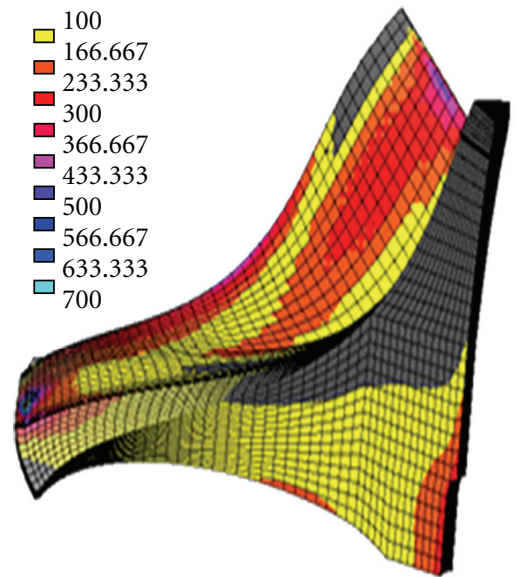

-4-degree lean

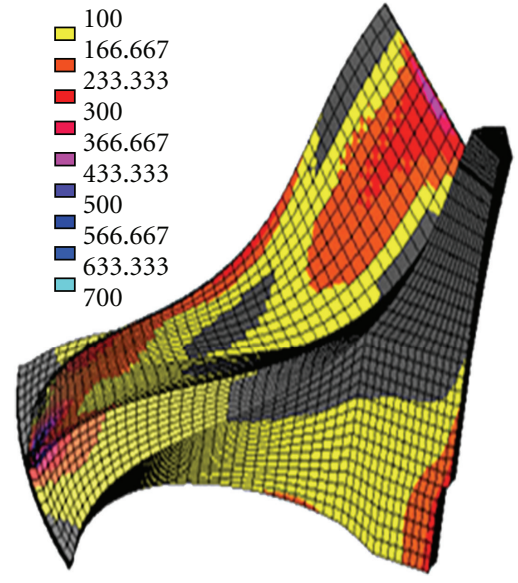

No lean
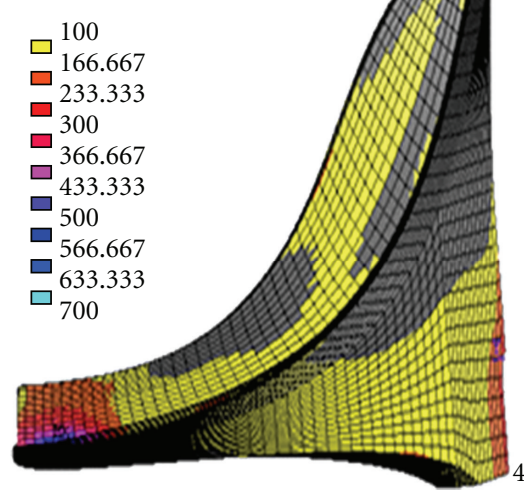

4-degree lean

FIgURE 17: Von Mises stress at the suction side of the wheel.

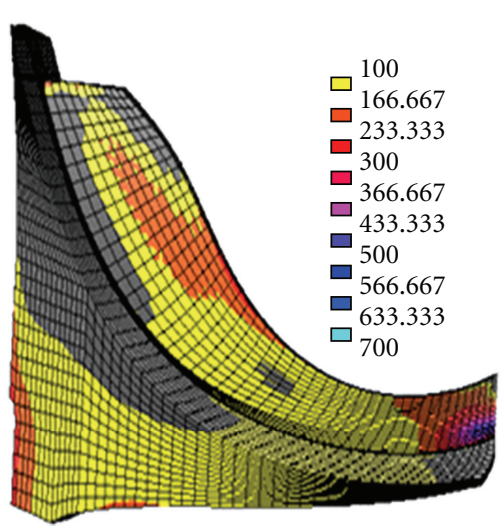

-4-degree lean

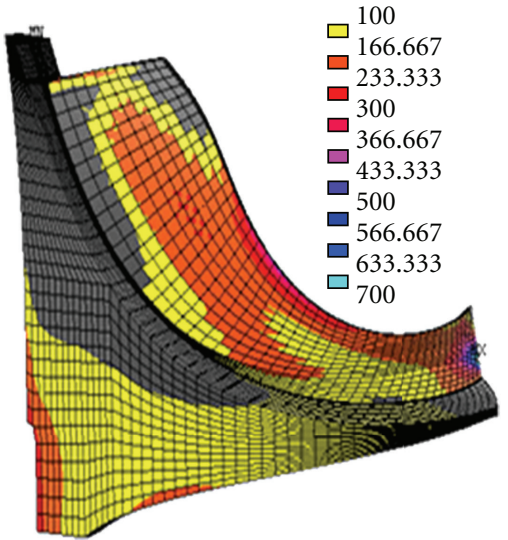

No lean

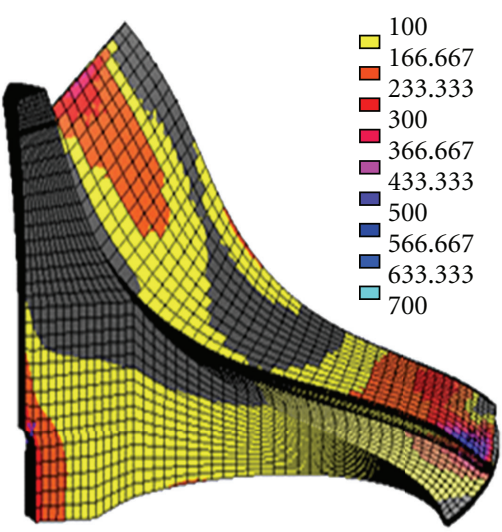

4-degree lean

Figure 18: Von Mises stress at the pressure side of the wheel.

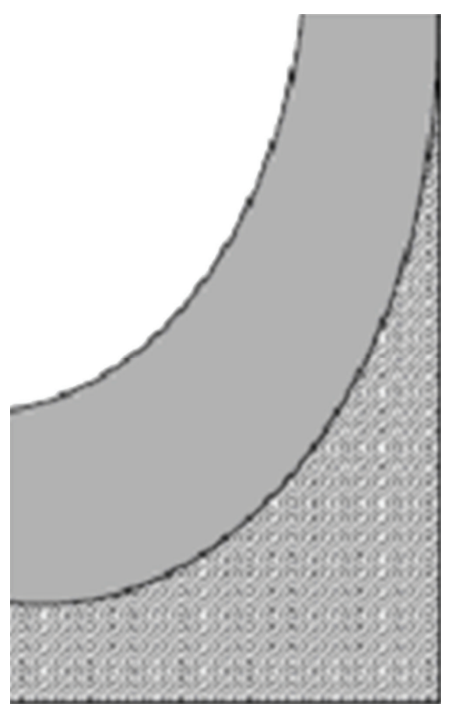

(a)

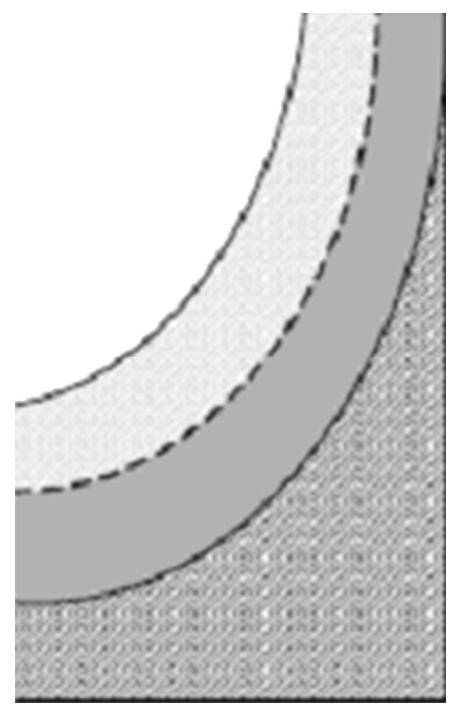

(b)

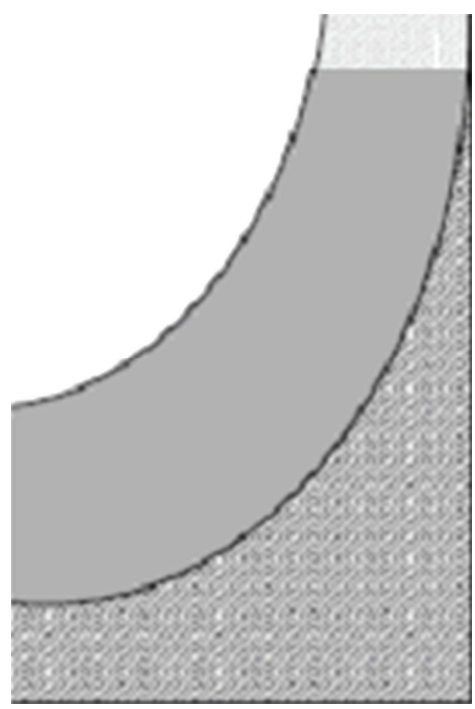

(c)

FIgUre 19: Flow cut of the impeller. 


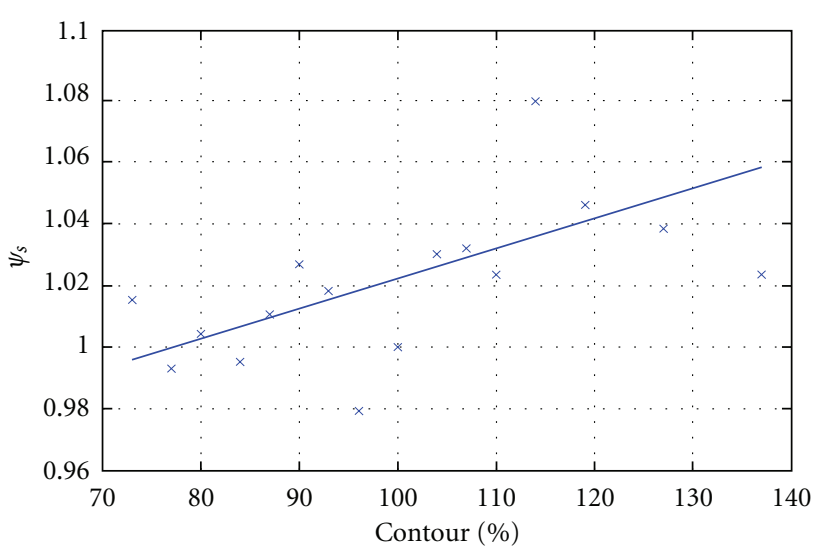

FIgURE 20: Head coefficient at the surge as a function of the contour.

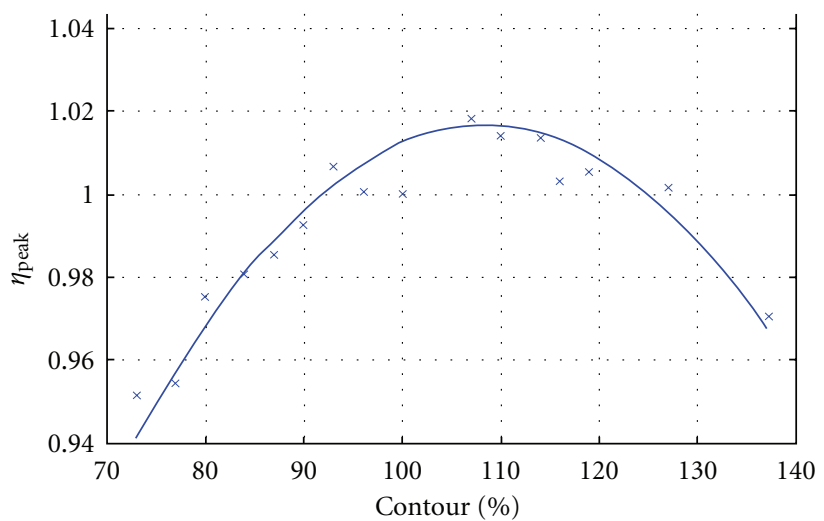

Figure 21: Peak efficiency change with flow cuts.

basic compressor characteristics for the diameter cut is also very helpful. Figure 23 is the medium back-curvature impeller compressor (about 25 degree back-curvature) characteristics of a diameter cut. It can be seen that the diameter cut not only affect the peak efficiency but also affect the peak efficiency location. The impeller peak efficiency of a small diameter impeller is located in the lower pressure ratio operating point. It also can be seen that the compressor operating range is reduced after the diameter cut. It is interesting to notice that the surge boundary slope increases with the diameter decrease.

\section{Ported Shroud Impeller Casing}

A compressor surge is a system-unstable phenomenon that is influenced by all components of the compressor. The physics of surge and stall are still not fully understood. We still cannot find any tool that can capture all features of the surge and stall, as shown in Figure 24. Many theoretical studies [27, 30, $31,44]$ have focused on a better understanding of the surge and stall, but none can be used as a design tool yet. More theoretical work and experimental studies need to be done in order to incorporate stall in the design system. Designs for a wide operating range were mainly dependent on engineers'

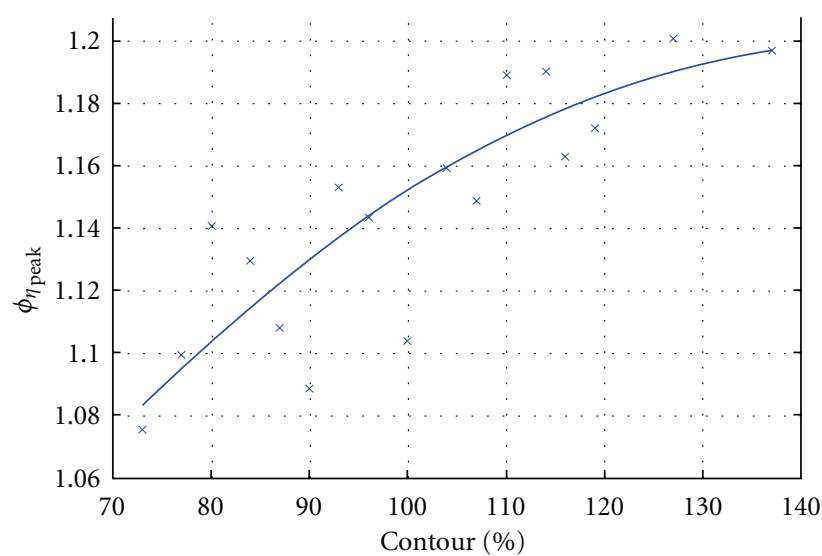

FIGURE 22: Flow coefficient at the peak efficiency versus the flow contours.

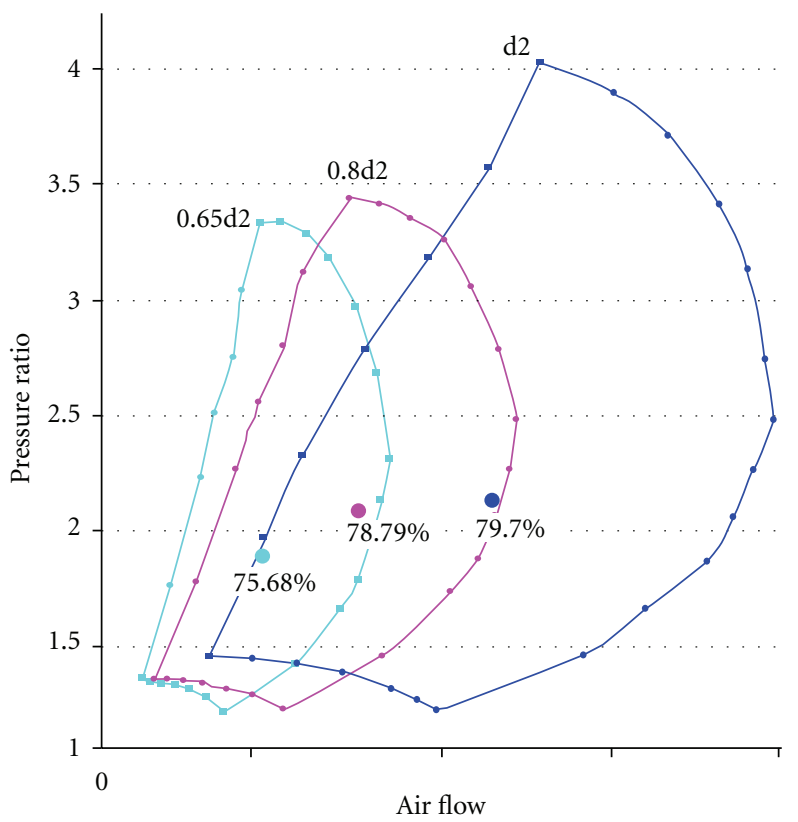

FIgURE 23: Performance characteristics of an impeller diameter cut.

and manufacturers' experience and their understanding of the stall and surge. Rotating stall and surge are violent limit cycle-type oscillations in compressors, which result when perturbations (in flow velocity, pressure, etc.) become unstable. Originally treated separately, these two phenomena are now recognized to be coupled oscillation modes of the compression system — surge that is the zeroth order or planar oscillation mode, while a rotating stall is the limit cycle resulting from higher-order, rotating-wave disturbances, as shown in Figure 24. The compressor normally starts with a stall and then eventually become a surge, as shown in Figure 25. During the surge, the compressor can experience a reversing flow. System resistance releases after the flow reversal, and the flow starts flowing into the system. This surge cycle continues, as shown in Figure 25. The pressure variation rate with the mass flow rate variation is much larger 


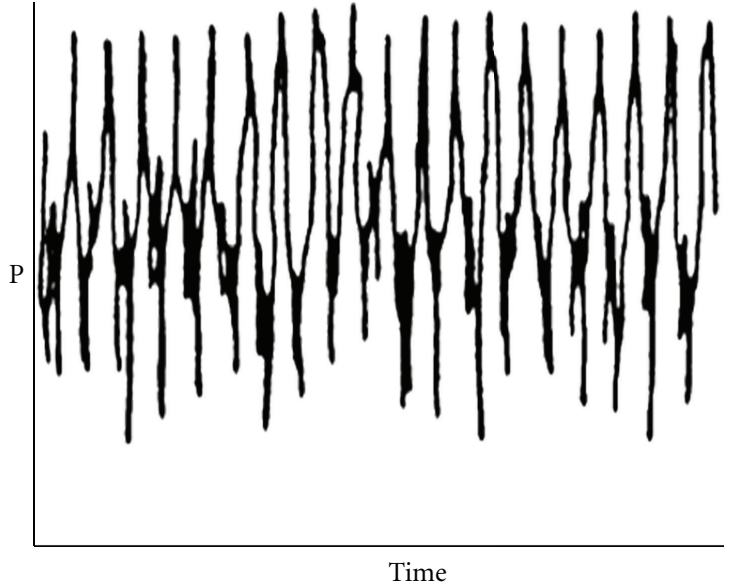

(a) Discharge pressure at stall

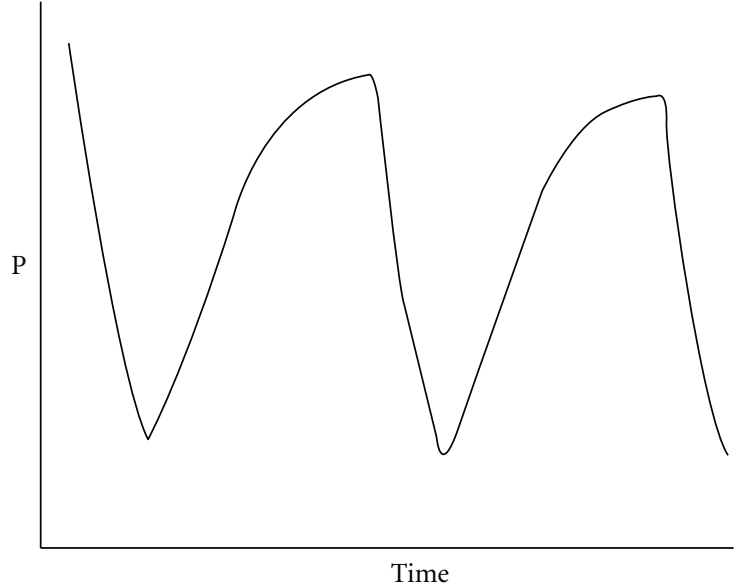

(b) Discharge pressure at surge

FIGURE 24: Stall and surge pressure variation with time.

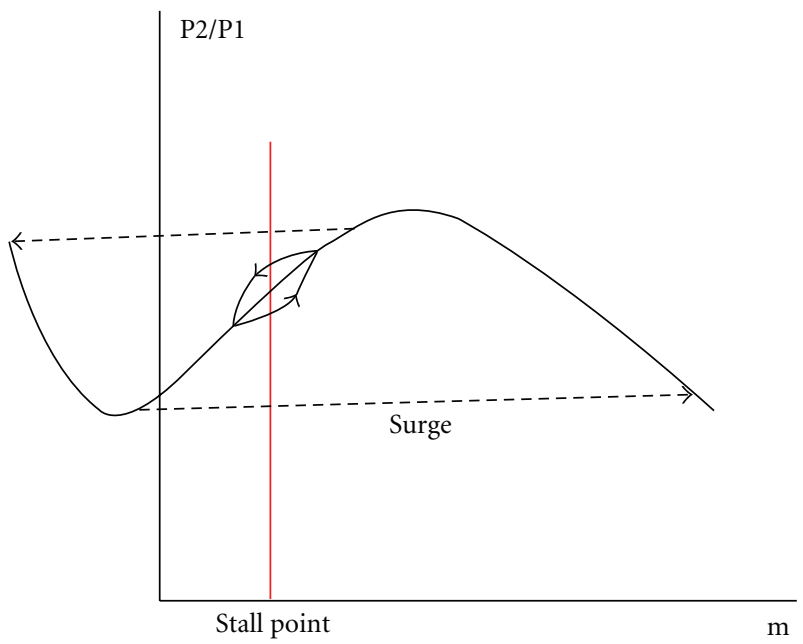

FIGURE 25: Surge of the centrifugal compressor.

than the near choke, as shown in Figure 26. To extend the surge margin, it is important to optimize the impeller, the vaned diffuser, the vaneless diffuser, and the volute design. The surge control can extend the surge margin further. The simplest the way is to have a bypass surge relief valve. When the centrifugal compressor pressure rises beyond a certain level, the valve bypasses the flow from the discharge to the inlet to prevent surge. A wise valve choice can help engineers pay for the rest of an advanced surge-control system without exceeding the budget. The valve needs to have a fast stroking speed when open, high capacity, low noise, and a very stable throttling control. For example, the oil and gas industry often chooses high-performance rotary valves.

Casing treatments are other popular methods to extend the centrifugal compressor range. One of the key casing treatments is a ported shroud casing, as shown in Figure 27. The ported shroud design is entirely passive, having no moving parts, control valves, and so forth, The ported slot can be

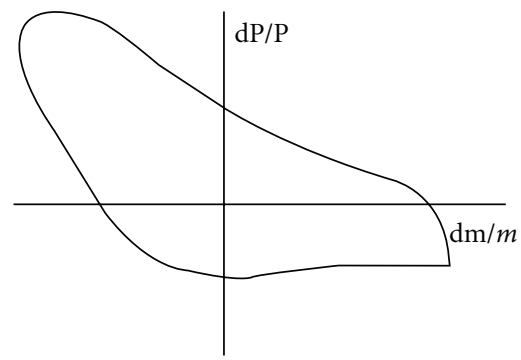

FIGURE 26: Variation of mass flow rate versus pressure fluctuations.

vertical to the inlet flow or angled, as shown in Figures 27(a) and $27(\mathrm{~b})$. There are vanes or ribs to support the stationary shroud in the leading edge inducer region. The vanes or ribs are not only a support structure but also an aerodynamic device to the flow inside the port, bleeding out with minimum losses. The ported shroud passage provides the bleed path when the compressor is near the surge, as shown in Figure 28(a) and also a secondary air inlet to the impeller when the compressor needs more air, as shown in Figure 28(b). The vanes or ribs in the passage are tangentially slanted in the direction of the impeller rotation, to preferentially augment the airflow into the impeller at high speed, while in partspeed discouraging the airflow out of the impeller through the secondary inlet. The advantage of the ported shroud can increase in the part-load surge margin and increase the choke flow at full load, as shown in Figure 29. It can be seen that for a ported shroud compressor, at a lower mass flow the pressure ratio increases. This is because the separation and reverse flow were reduced near the inducer compared with an unported case. When the compressor is near choke, the impeller can bypass the impeller throat and draw an extra flow from the port, as shown in Figure 28(b). Figure 30 shows that the flow passed the port at different impeller mass flow conditions when the port width and location were optimized to have the best surge margin for a gas width equal to bg. 


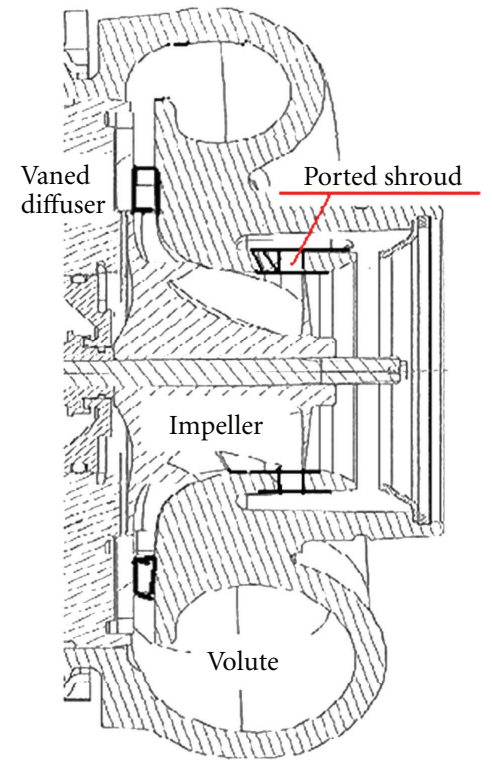

(a) Straight ported shroud

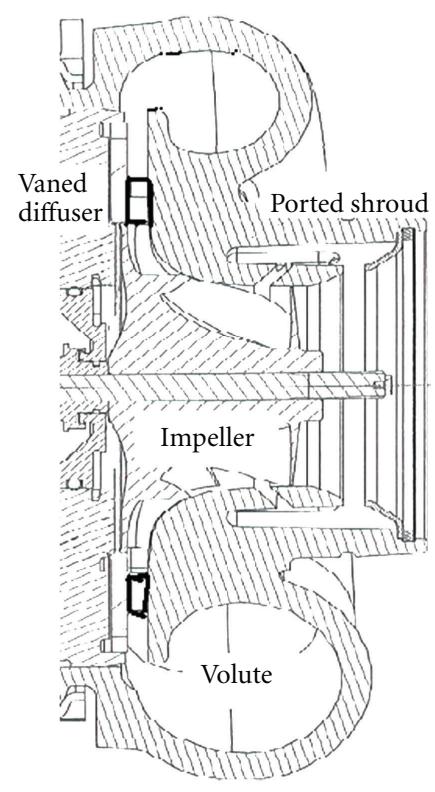

(b) Angle ported shroud

Figure 27: Ported shroud compressor.

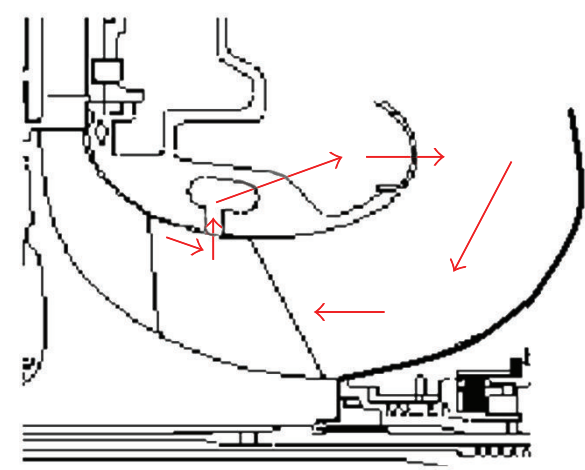

(a) Near surge

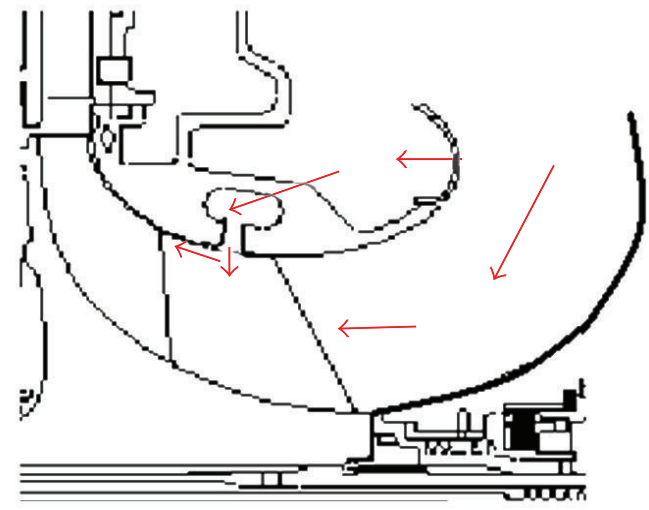

(b) Near choke

FIGURE 28: Ported shroud flows.

It can be seen that the port recirculation flow increases when the compressor mass flow reduces. The port can pass as much as $40 \%$ of the impeller design flow. It can be seen from Figure 30 that the port recirculation flow reduces when the port width reduces. Figure 31 is the port width affecting the compressor performance for a ported compressor with the port location at $16 \%$ of the shroud meridional length from the impeller inducer. It can be seen that when the port location is fixed, the port width increases from 0 to $0.6 b_{2}$, and both the surge margin and choke margin increase. The com-pressor adiabatic efficiency remains almost unchanged until the port width is larger than $0.1 b_{2}$. The efficiency drops almost negligibly up to a port width larger than $0.2 b_{2}$. Figure 31 also shows that the angle port (70 degree with axial direction) has an advantage compared with a straight port. The port design goal is to improve the surge and choke margin without greatly affecting the compressor performance. In some applications, for example, the automobile and aviation industry, the surge margin, and choke margins are both defined by certain efficiency levels. If the efficiency is too low, the system cannot perform properly. For those applications, the ported shroud applications are very popular. The ported shroud not only can extend the operational margin but also can improve the efficiency near the choke and surge. For those applications, the compressor map for a ported shroud demonstrated more advantages than an unported compressor, as shown in Figure 32 . 


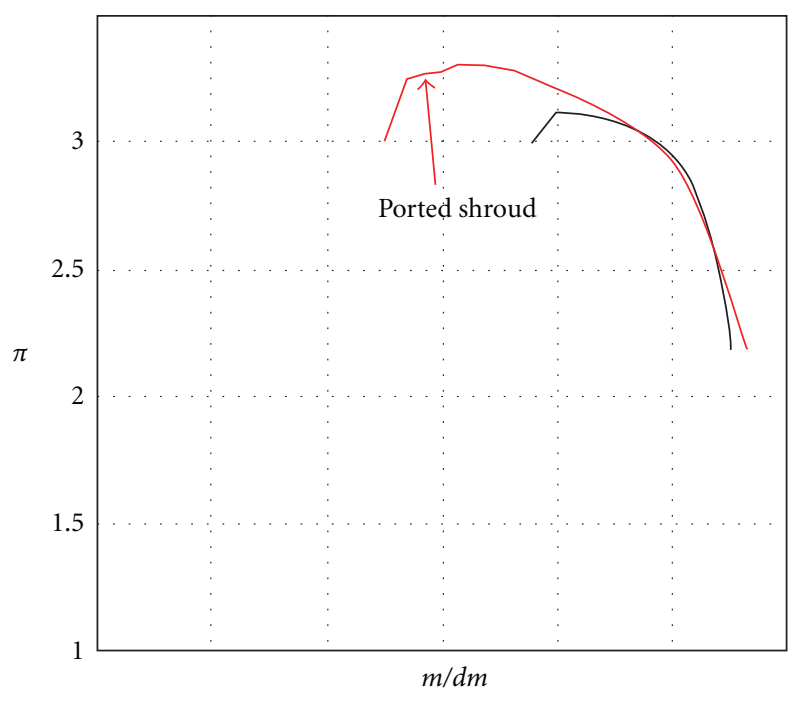

FIgURE 29: Compressor characteristic with and without ported shroud.

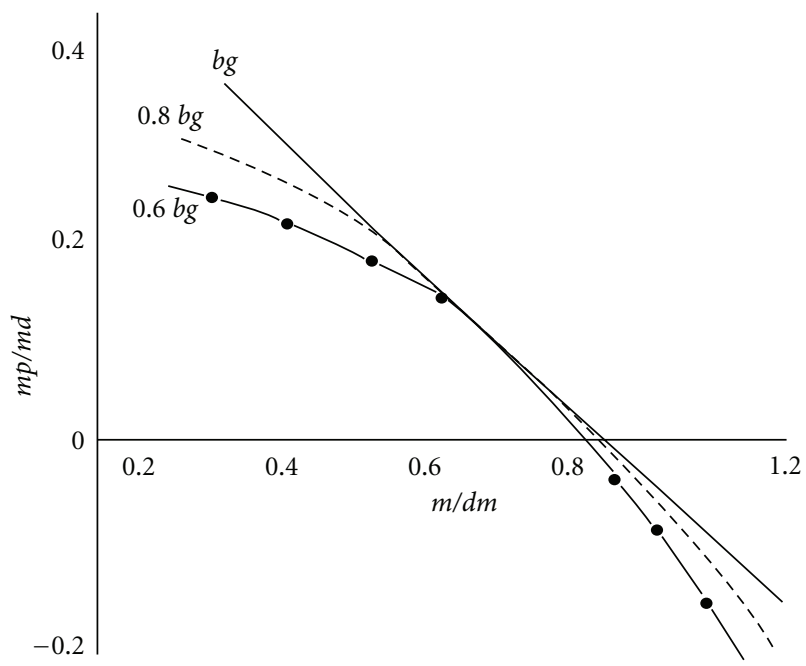

Figure 30: Flow inside bleed out from the port.

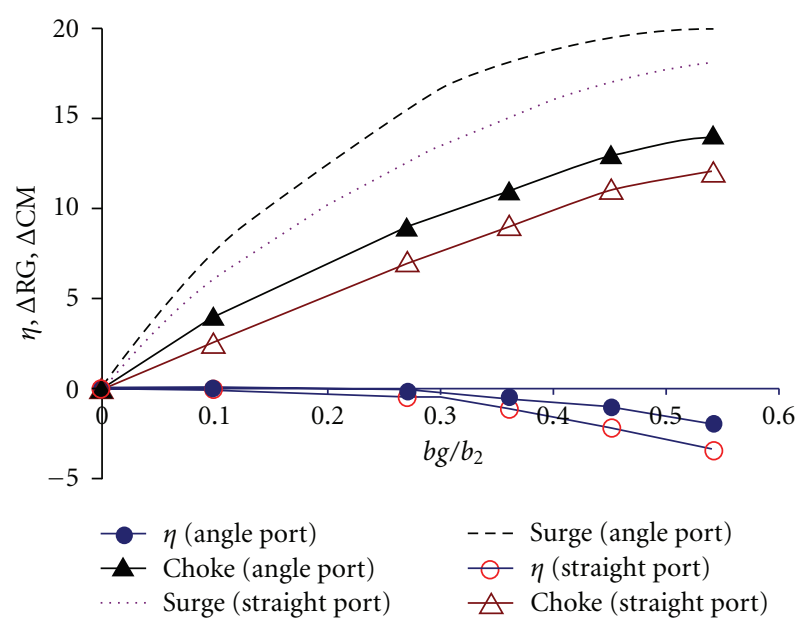

FIGURE 31: The compressor performance versus port width.

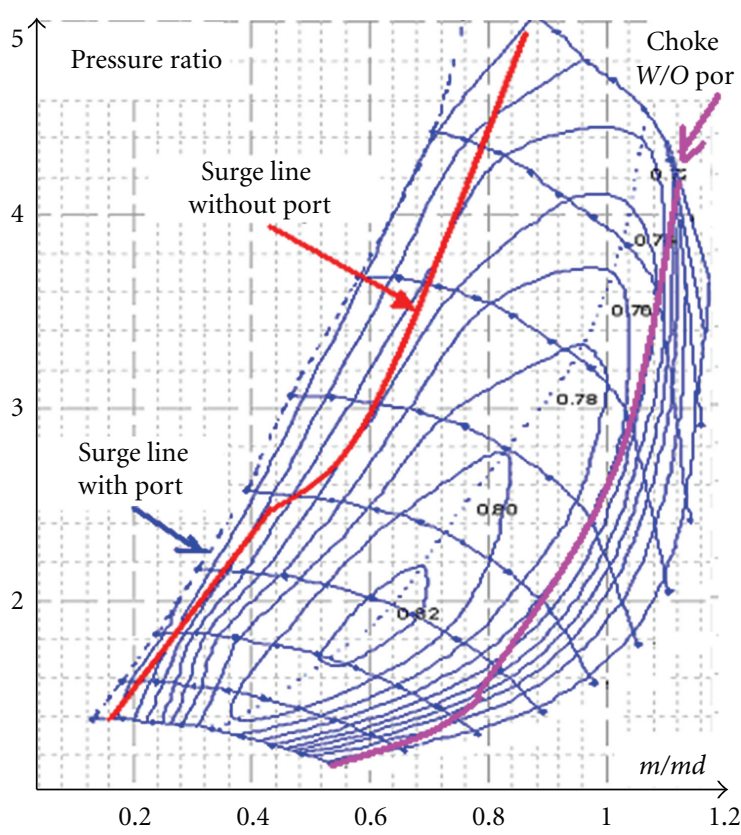

Figure 32: Ported shroud compressor map.

\section{Conclusions}

This paper provides several empirical consideration points in designing centrifugal compressors, focusing on the impeller design.

(1) The different structure split compressors are discussed.

(2) In an initial stage of compressor design, selections of the impeller inlet and the outlet velocity vectors and choice of blade numbers are the key initial design decisions.

(3) Leaning the blades creates a back sweep and retains purely radial fibers, which are beneficial for bending moments. Experience showed that impellers with a back sweep generally have high efficiency. But lean blade design needs to consider the impacts of the impeller structure.

(4) The velocity profile through the impeller blades largely depends on the flow Reynolds number. For low Reynolds number flows, the exit velocity profiles are almost parabolic and only with a small portion of the flat profile. For high Reynolds number flows, the exit velocity profiles have large flat profiles.

(5) The tip clearance affects the overall compressor performance because it increases the magnitude of the secondary flow inside the impeller blades and produces strong tip vortices.

(6) The tip clearance setting depends on the compressor's maximum surplus value. There are several methods to reduce the tip clearance losses. A variable tip clearance is one of the potential designs. 
(7) Compressor impeller flow cuts are widely used by compressor manufacturers. Some performance impacts need to be considered for doing the flow cut.

(8) The ported shroud compressor has advantages for the compressor performance. Many new ported shroud structures have been proposed by many compressor manufactures [24]. But some fundamentals discussed in this paper can help designers to make the right decisions.

\section{Nomenclature}

$B_{2}, b_{2}$ : Impeller tip width $(\mathrm{m})$

$C_{1}$ : Inlet axial velocity $(\mathrm{m} / \mathrm{s})$

$C_{P}: \quad$ Pressure coefficient $=p /\left(0.5 \rho d_{2} U_{2}{ }^{2}\right)$

CM: Choke margin

DF: Diffusion factor

$D_{s}$ : $\quad$ Specific diameter

dm: Flow fluctuations $(\mathrm{kg} / \mathrm{s})$

$\mathrm{dp}$ : Pressure fluctuations (pa)

F: $\quad$ Function

$f: \quad$ Friction factor

$H: \quad$ Head $(\mathrm{m})$

ICFM: Cubic foot per minute at inlet

$K: \quad$ Sand grain roughness $(\mu \mathrm{m})$

$L: \quad$ Blade meridional length $(\mathrm{m})$

$m$ : $\quad$ Mass flow rate $(\mathrm{kg} / \mathrm{s})$

$N: \quad$ Rotational speed (RPS)

$r$ : $\quad$ RMS radius (m)

Re: Reynolds number

ICFM: Compressor inlet flow in $\mathrm{ft} / \mathrm{min}$.

M: $\quad$ Mach number

MR: Mach number ratio

Mu: $\quad$ Head coefficient $=H /\left(D_{2} N\right)^{2}$

$Q: \quad$ Volume metric flow rate $\left(\mathrm{m}^{3} / \mathrm{s}\right)$

$\mathrm{RG}$ : Operating range $=\left(Q_{c}-Q_{s}\right) / Q_{c}$

RMS: Root mean square

$u, v: \quad$ Velocities $(\mathrm{m} / \mathrm{s})$

$V: \quad$ Velocity vector

$W: \quad$ RMS-relative velocity $(\mathrm{m} / \mathrm{s})$

$x, y: \quad$ Cartesian coordinates.

\section{Greek Symbols}

$\mu$ : Viscosity (pa.s)

$\varphi$ : Flow coefficient $=Q /\left(N D^{3}\right)$

$\eta$ : Adiabatic efficiency (total to static $)=$ $\left(\pi^{(\gamma-1 / \gamma)}-1\right) /\left(\mathrm{T}_{2} / \mathrm{T}_{01}-1\right)$

$\Psi$ : Head coefficient $=h / u_{2}{ }^{2}$

$\pi$ : Pressure ratio

$\gamma$ : Specific heat ratio.

\section{Subscripts}

1, 2: Impeller inlet and exit

C: Chock or clearance l: $\quad$ Loss

0: Zero clearance

ref: Reference

S: Surge.

\section{References}

[1] M. P. Singh and J. J. Vargo, "Reliability evaluation of shrouded blading using the SAFE interference diagram," Journal of Engineering for Gas Turbines and Power, vol. 111, no. 4, pp. 601609, 1989.

[2] D. P. Kenny, The history and future of the centrifugal compressor in aviation gas turbine, SAE/SP-804/602, 1984.

[3] P. D. Collopy, "Surplus value in propulsion system design optimization," AIAA-97-3159, 1997.

[4] D. Japikse, "Decisive factors in advanced centrifugal compressor design and development," in Proceedings of the International Mechanical Engineering Congress \& Exposition (IMechE '00), November 2000.

[5] C. Xu and R. S. Amano, "Development of a low flow coefficient single stage centrifugal compressor," International Journal of Computational Methods in Engineering Science and Mechanics, vol. 10, no. 4, pp. 282-289, 2009.

[6] C. Rodgers and L. Sapiro, "Design considerations for highpressure ratio centrifugal compressor," 72-GT-71, 1972.

[7] R. H. Aungier, Centrifugal Compressors - A Strategy for Aerodynamic Design and Analysis, ASME Press, New York, NY, USA, 2002.

[8] C. Xu, "Design experience and considerations for centrifugal compressor development," Proceedings of the Institution of Mechanical Engineers, Part G, vol. 221, no. 2, pp. 273-287, 2007.

[9] C. Xu and R. S. Amano, "A hybrid numerical procedure for cascade flow analysis," Numerical Heat Transfer, Part B, vol. 37, no. 2, pp. 141-164, 2000.

[10] C. Xu and R. S. Amano, "Flux-splitting finite volume method for turbine flow and heat transfer analysis," Computational Mechanics, vol. 27, no. 2, pp. 119-127, 2001.

[11] C. Xu and R. S. Amano, "Computational analysis of pitchwidth effects on the secondary flows of turbine blades," Computational Mechanics, vol. 34, no. 2, pp. 111-120, 2004.

[12] C. Xu and R. S. Amano, "Numerical prediction of swept blade aerodynamic effects," in Proceedings of ASME Turbo \& Expo, pp. 1-9, Vienna, Austria, June 2004, GT2004-53008.

[13] C. Xu and R. S. Amano, "Computational analysis of swept compressor rotor blades," International Journal of Computational Methods in Engineering Science and Mechanics, vol. 9, no. 6, pp. 374-382, 2008.

[14] C. Xu and R. S. Amano, "The development of a centrifugal compressor impeller," International Journal of Computational Methods in Engineering Science and Mechanics, vol. 10, no. 4, pp. 290-301, 2009.

[15] C. Xu and R. S. Amano, "Computational analysis of scroll tongue shapes to compressor performance by using different turbulence models," International Journal of Computational Methods in Engineering Science and Mechanics, vol. 11, no. 2, pp. 85-99, 2010.

[16] C. Xu and R. S. Amano, "Study of the flow in centrifugal compressor," The International Journal of Fluid Machinery and Systems, vol. 3, no. 3, pp. 260-270, 2010. 
[17] H. Krain, B. Hoffmann, and H. Pak, "Aerodynamics of a centrifugal compressor impeller with transonic inlet conditions," in Proceedings of the International Gas Turbine and Aeroengine Congress and Exposition, June 1995, 95-GT-79.

[18] H. Krain, "Flow in centrifugal compressor," von Karman Institute for Fluid Dynamics, Ls 17, 1984-07, 1984.

[19] D. Japikse, Centrifugal Compressor Design and Performance, Concepts Eti, Wilder, Vt, USA, 1996.

[20] C. Xu and R. S. Amano, "On the development of turbomachine blade aerodynamic design system," International Journal of Computational Methods in Engineering Science and Mechanics, vol. 10, no. 3, pp. 186-196, 2009.

[21] E. Benini and A. Toffolo, "Centrifugal compressor of a $100 \mathrm{~kW}$ microturbine: part 2-numerical study of impeller-diffuser interaction," in Proceedings of the ASME Turbo Expo, pp. 699705, June 2003, GT-2003-38153.

[22] E. Benini and A. Toffolo, "Centrifugal compressor of a $100 \mathrm{~kW}$ microturbine: part 3-optimization of diffuser apparatus," in Proceedings of the ASME Turbo Expo, pp. 707-714, June 2003, GT-2003-38154.

[23] J. Hoffren, T. Siikonen, and S. Laine, "Conservative multiblock Navier-Stokes solver for arbitrarily deforming geometries," Journal of Aircraft, vol. 32, no. 6, pp. 1342-1350, 1995.

[24] T. Siikonen, "An application of Roe's flux-difference splitting for k- $\varepsilon$ turbulence model," International Journal for Numerical Methods in Fluids, vol. 21, no. 11, pp. 1017-1039, 1995.

[25] M. M. Rai, "A relaxation approach to patched-grid calculations with the euler equations," Journal of Computational Physics, vol. 66, no. 1, pp. 99-131, 1986.

[26] S. Niazi, A. Stein, and L. N. Sankar, "Development and application of a CFD solver to the simulation of centrifugal compressors," AIAA paper 98-0934, 1998.

[27] W. Jansen, "Rotating stall in a radial vaneless diffuser," ASME Journal of Basic Engineering, vol. 86, pp. 750-758, 1964.

[28] Y. Senoo and Y. Kinoshita, "Influence of inlet flow conditions and geometries of centrifugal vaneless diffusers on critical flow angle for reverse flow," ASME Journal of Fluids Engineering, vol. 99, no. 1, pp. 98-103, 1977.

[29] H. S. Dou and S. Mizuki, "Analysis of the flow in vaneless diffusers with large width-to-radius ratios," ASME Journal of Turbomachinery, vol. 120, no. 1, pp. 193-201, 1998.

[30] S. Ljevar, H. C. de Lange, and A. A. van Steenhoven, "Twodimensional rotating stall analysis in a wide vaneless diffuser," International Journal of Rotating Machinery, vol. 2006, Article ID 56420, 11 pages, 2006.

[31] K. Iwakiri, M. Furukawa, S. Ibaraki, and I. Tomita, "Unsteady and three-dimensional flow phenomena in a transonic centrifugal compressor impeller at rotating stall," in Proceedings of the ASME Turbo Expo, pp. 1611-1622, June 2009, GT200959516.

[32] E. M. Greitzer, "Review_axial compressor stall phenomena," ASME Journal of Fluids Engineering, vol. 102, no. 2, pp. 134 151, 1980.

[33] M. T. Barton, M. L. Mansour, J. S. Liu, and D. L. Palmer, "Numerical optimization of a vaned shroud design for increased operability margin in modern centrifugal compressors," ASME Journal of Turbomachinery, vol. 128, no. 4, pp. 627-631, 2006.

[34] ASME, Performance Test Code on Compressors and Exhausters, PTC 10-97, 1997.

[35] R. S. Amano and B. Sunden, Thermal Engineering in Power Systems, WIT Press, 2008.
[36] O. E. Balje, Turbamachines, John Wiley \& Sons, New York, NY, USA, 1981.

[37] K. Brun and R. Kurz, "Analysis of secondary flows in centrifugal impellers," International Journal of Rotating Machinery, vol. 2005, no. 1, pp. 45-52, 2005.

[38] R. L. Street, G. Z. Watters, and J. K. Vennard, Elementary Fluid Mechanics, John Wiley \& Sons, New York, NY, USA, 1996.

[39] T. Wright, "Comments on compressor efficiency scaling with Reynolds number and relative roughness," in Proceedings of the American Society of Mechanical Engineers, June 1989, 89-GT31.

[40] P. R. N. Childs and M. B. Noronha, "The impact of machining techniques on centrifugal compressor impeller performance," in Proceedings of the International Gas Turbine \& Aeroengine Congress \& Exposition, June 1997, 97-GT-456.

[41] C. Rodgers, A diffusion factor correlation for centrifugal impeller stalling, 78-GT-61, 1978.

[42] C. Xu and R. S. Amano, "A turbo machinery blade design and optimization procedure," GT-2002-30541, 2002.

[43] D. P. Kenny, The history and future of the centrifugal compressor in aviation gas turbine, SAE/SP-804/602, 1984.

[44] R. van den Braembussche, "Rotating stall in centrifugal compressors," VKI Preprint 1987-16, 1987. 

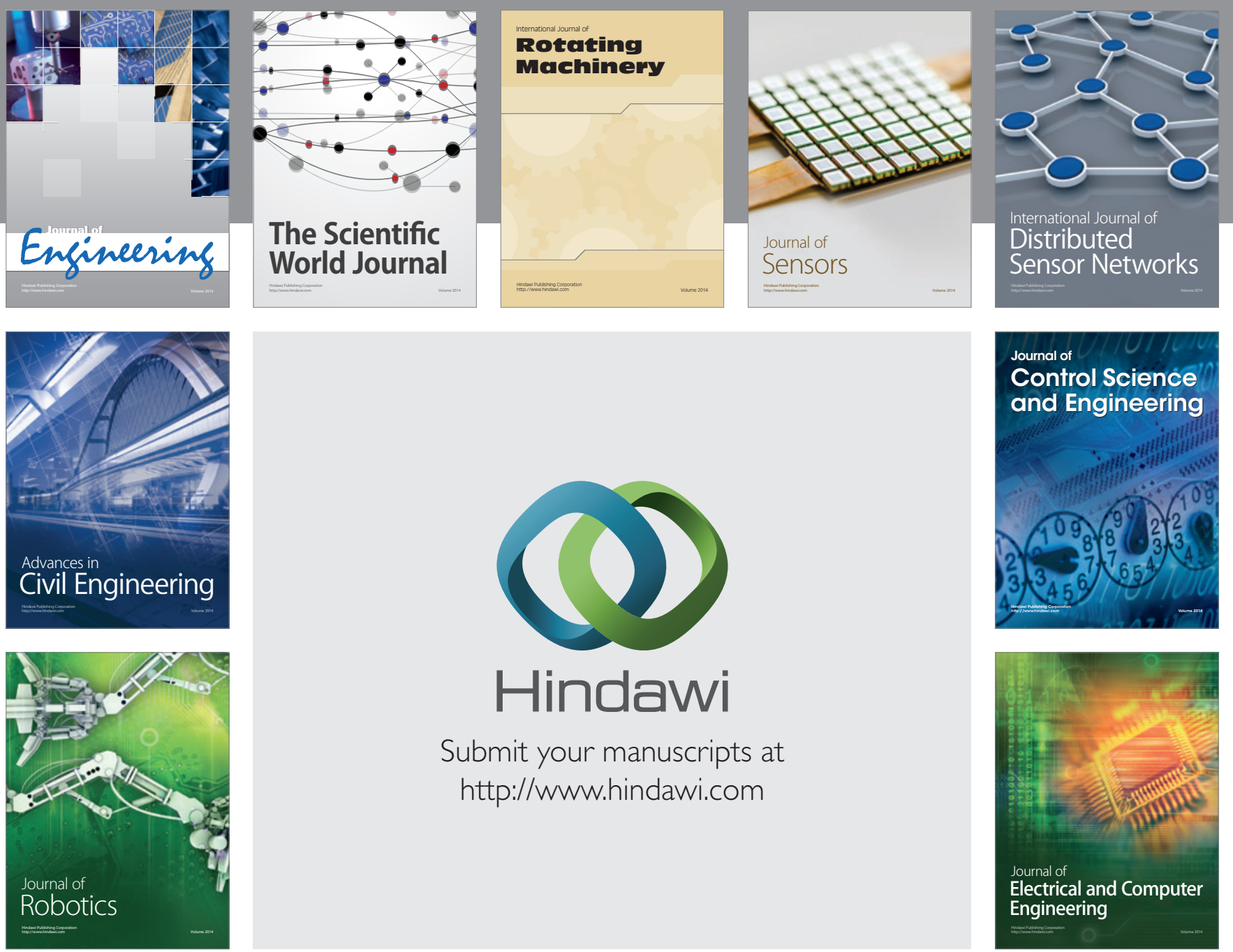

Submit your manuscripts at

http://www.hindawi.com
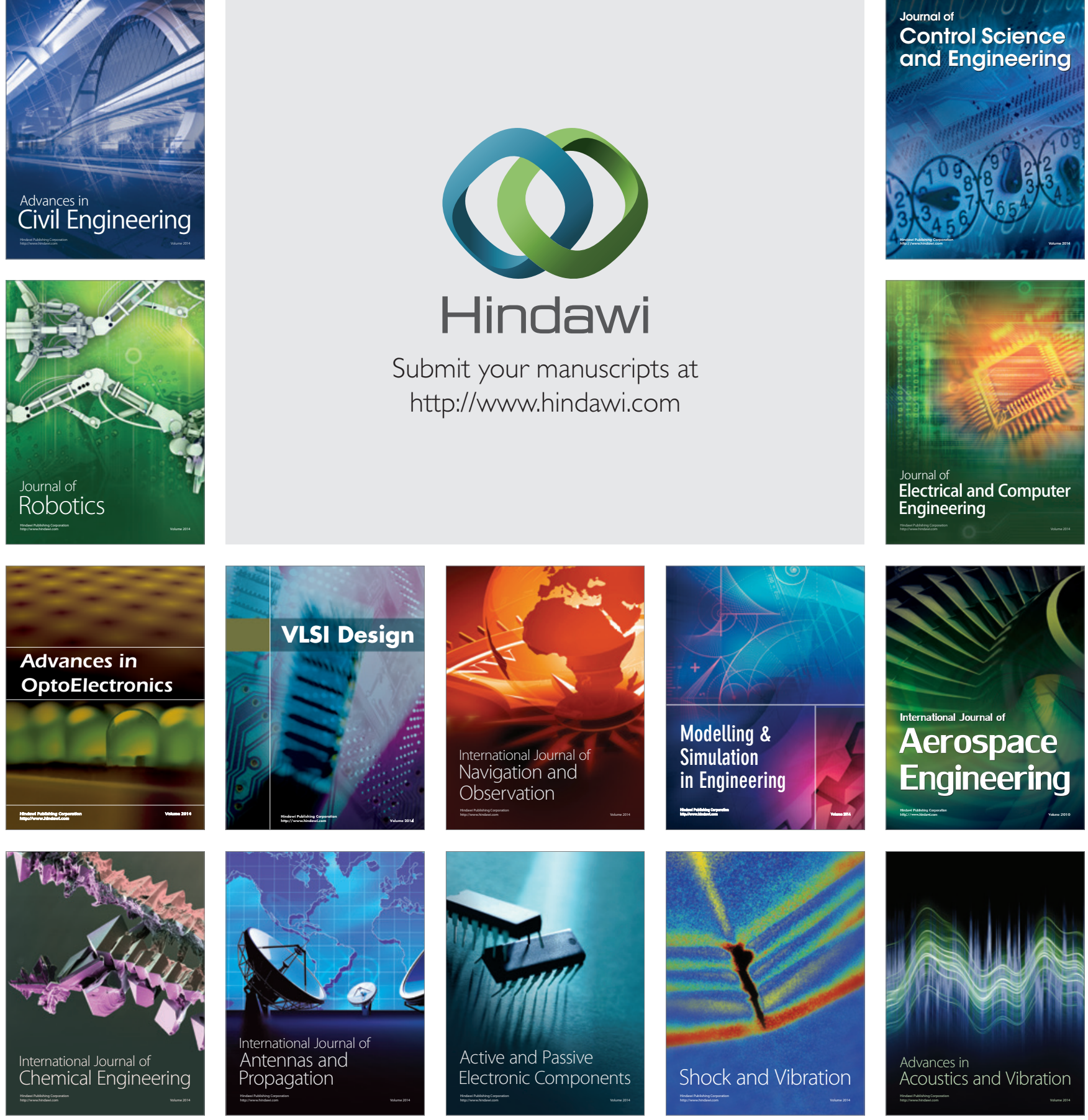